\title{
Value of Extracellular High Mobility Group Box 1 (HMGB1) in the Clinical Context of Immune Thrombocytopenia
}

\author{
Elif G Umit ${ }^{1}$, Mehmet Baysal ${ }^{1}$, Volkan Bas ${ }^{1}$, Hasan Goze ${ }^{2}$, Veysi Asoglu ${ }^{2}$, Onur Kirkizlar ${ }^{1}$, \\ Ahmet Muzaffer Demir ${ }^{1}$
}

${ }^{1}$ Trakya University Faculty of Medicine, Department of Hematology, Edirne, Turkey

${ }^{2}$ Trakya University Faculty of Medicine, Department of Internal Medicine, Edirne, Turkey

\section{Correspondence:}

Elif G Umit

Address: Trakya University Faculty of Medicine, Department of Hematology, Edirne, Turkey Email: egugur@yahoo.com
Received: 02.04.2019, Accepted: 30.05 .2019 https://doi.org/10.5799/jcei/5833

\begin{abstract}
Introduction: High mobility group box 1 protein (HMGB1) is a non-histone chromosomal protein with dual activity. First within the nucleus, binds to DNA and acts as a regulator and second, outside the cell, interacts with receptors for inflammation as a signal molecule. We aimed to investigate and contribute to the value of extracellular HMGB1 in clinical context of ITP and to flourish future clinical directions to this biomarker.
\end{abstract}

Methods: 50 newly diagnosed and treatment naive patients with ITP and 30 healthy controls were enrolled in our study.

Results: Age or gender were not related with HMGB1 levels in patients and controls. Platelet levels were significantly related with HMGB1. Especially in patients with platelet counts below $30.000 / \mathrm{mm} 3$ highest levels of HMGB1 were observed. Regarding clinical presentation, bleeding was related with low platelet counts and high HMGB1 levels. Response to corticosteroids was observed to be better in patients with high HMGB1 levels.

Conclusion: As a sample of autoinflammatory disorders, we observed a relation with extracellular HMGB1 levels and platelet levels in ITP patients. Corticosteroid response and HMGB1 relation supports the assumption of the value of HMGB1 as a potential surrogate of inflammation. This view should be evaluated with larger scale studies.

Keywords: immune thrombocytopenia, inflammation, cytokine

\section{INTRODUCTION}

High-group box 1 protein (HMGB1) is a non-histone chromosomal protein. Recognized in the 70s as small as a protein but larger in quantity, HMGB1 has found its credit in the last decade [1]. Within the nucleus HMGB1 acts as an architectural factor of DNA-dependent processes by binding to DNA including telomere homeostasis. The second venue of HMGB1 is outside the cell, as a signal molecule, a.k.a alarmine, HMGB1 interacts with intranuclear receptors to transmit signals. One of the intracellular receptors of HMGB1 is receptor for advanced glycation end products (RAGE) which binding to HMGB1, starts an activation of pathways regarding diabetes and complications, atherosclerosis, neurological disorders, rheumatoid arthritis and cancer [2]. Another receptor for HMGB1 is Toll-Like Receptors (TLRs) 2, 4 and 9 which activate $\mathrm{NF}-\mathrm{kB}$ pathway and are involved in inflammation [3]. More specifically, HMGB1-TLR2 complex activates NK cells [4] and HMGB1-TLR4 signaling is involved in anticancer immunity [5].

As the interest in HMGB1 kept increasing, new receptors and new pathways for HMGB1 were defined. HMGB1 is observed to be a damage recognition protein and mediates the antitumor effects of cisplatin, which is used for various solid and hematological tumors in a cytotoxic manner. Besides the findings of cisplatin therapy, HMGB1 is observed to be increased in tumoral tissues compared to normal tissues in cancer types including leukemia, 
hepatocellular carcinoma and gastrointestinal carcinomas [2] and suggested to be a probable cancer repair protein.

Outside the cell, HMGB1 is classified within the DAMP molecular family [6] and the release of HMGB1 may lead to the termination of the cell. As mentioned above, HMGB1 binds to TLRs and participate the activation of NF-kB signaling pathway. Inhibiting HMGB1-mediated inflammation is suggested to be an investigational target to develop therapeutics via TLR4-cytokine pathway [7]. In various inflammatory conditions including sepsis, hepatitis, neurological and pulmonary diseases, HMGB1 is investigated and reported to participate the pathogenesis. Besides the immune responses related with self recognition, extracellular HMGB1 is also related with tumor immunity including the signalization of tumor microenvironment, tumor development and invasion [8].

Regarding the disorder of our interest, ITP, the position of HMGB1 has been investigated i a study demonstrating the expression of HMGB1 in the splenic tissues of chronic ITP patients with results suggesting a role of HMGB1 in the pathogenesis of ITP through antibody mediated immunity against platelets [9]. In our study, we aimed to investigate the value of extracellular HMGB1 in clinical context as a biomarker for clinicians, and as a piece to the unfinished pathogenetic puzzle of ITP.

\section{METHODS}

According to the consensus statement of ITP working group in 2009 and American Society of Hematology in 2011, 50 treatment naive and newly diagnosed patients with acquired primary ITP and 30 healthy age and sex matched controls were prospectively enrolled. The diagnostic criteria of primary ITP was defined as platelet count less than $100.000 / \mathrm{mm} 3$ in the abscence of any cause or concurrent disorder. Abnormalities in hemoglobin or white blood cell levels and morphology are not typical with ITP and should not be regarded as primary ITP. Any patients who had abnormal hemoglobin level or white blood cell count, who have been receiving immunosuppressive treatments for ITP or any other disorder, and had chronic or secondary ITP, and any patients receiving antiplatelet treatment were excluded $[10,11]$.

Samples for determination of HMGB1 were obtained at the time of diagnosis, concomitantly with the samples of whole blood counts, before treatment. Samples were centrifuged (5000 rpm for 3 minutes) and kept in a $-80^{\circ} \mathrm{C}$ freezer until study procedure.

Serum HMGB1 levels were measured with ELISA assay CK-E90195 kit (Hangzhou Eastbiopharm Co Ltd, P.R. China) according to the manufacture insert. Briefly, $100 \mu \mathrm{L}$ of sample diluent was added to each well and $10 \mu \mathrm{L}$ of standard; then sample or control was added to the well. Plates were incubated for 6 hours at $37^{\circ} \mathrm{C}$ After washing, 100 $\mu \mathrm{L} /$ well of HMGB1 monoclonal antibody for humans was added and the plates were once more incubated for 2 hours.
After washing, chromogen was added to each well. Reacton was allowed for 30 minutes at room temperature, with the addition of stop solution, the absorbance was read at $450 \mathrm{~nm}$. The results were calculated using calibration curve which is determined from standards. Blood counts were analyzed with Beckman Coulter LH 380 analyzer. Clinical data of patients were recorded from the files.

Treatment response evaluation was based on the IWG and ASH 2011 criteria as complete response (CR) defined as increase in platelet counts to $>100.000 / \mathrm{mm} 3$, response $(\mathrm{R})$ as increase in platelets to $>30.000 / \mathrm{mm} 3$ with at least two times of the basal count and without bleeding, no response (NR) as less than $30.000 / \mathrm{mm} 3$ or less than two times increase despite appropriate treatment, corticosteroid dependence (CD) as need for onging or repeated courses of corticosteroids to maintain platelet levels above 30.000 and/or avoid bleeding $[10,11]$.

The study was approved by the local ethical committee and written informed consent was obtained from all participants.

\section{STATISTICS}

The descriptive data are expressed as the means \pm the SDs. One-way analysis of variance was used to examine the differences in the normally distributed and continuous variables between the 3 groups. Kruskal-Wallis tests were used for the non-normally distributed variables. Chi-square analyses were used for categorical variables from the clinical characteristics data. The correlation was analyses were performed with Pearson correlation tests and likelihood ratio tests. One way ANOVA with Bonferroni and Tukey and Post Hoc tests were performed for HMGB1 levels and platelet count groups to determine intergroup variability. Statistical difference was defined by $\mathrm{P}<0.05$. The results were analyzed with SPSS21.0 software.

\section{RESULTS}

Within patients group, 34 were female $(68.0 \%)$ while 16 were male $(32.0 \%)$; and in control group 17 were female $(56.7 \%)$ and 13 were male $(43.3 \%)$. In the patient group, mean age was 53.56 years, mean values of platelet count 20.772/mm3, MPV $11.35 \mathrm{fL}$, and HMGB1 was 15173.4 $\mathrm{pg} / \mathrm{mL}$. In the control group, mean age was 53.23 years, mean values of platelet count $251.900 / \mathrm{mm} 3, \mathrm{MPV} 8.7 \mathrm{fL}$ and HMGB1 was $5606.06 \mathrm{pg} / \mathrm{mL}$. In patients group, 38 patients had platelet counts $<30.000 / \mathrm{mm} 3$, and 12 patients had $30.000-99.000 / \mathrm{mm} 3$. Age or gender were not related with HMGB1 levels in both groups.

\section{Platelet Counts and HMGB1}

Platelet levels were significantly related with HMGB1, showing a dramatic increase with the decrease of platelet counts $(p=0.001$ with a correlation coefficient [cc] -0.689). Especially in patients with platelet counts $\leq 30.000 / \mathrm{mm} 3$, which require treatment, the highest levels of HMGB1 were observed ( $\mathrm{p}$ value $=0.001, \mathrm{cc}-0.748$ ). Likewise, increased 
Inflammatory Pathways of ITP

Table 1. General features of patients and HMGB1 relations

\begin{tabular}{|c|c|c|c|}
\hline & \multicolumn{2}{|l|}{ Patient Group $(n=50)$} & Control Group ( $n=30)$ \\
\hline Age (mean, years) & \multicolumn{2}{|l|}{$53.56( \pm 20.41)$} & $53.23( \pm 15.64)$ \\
\hline Gender (F/M) & \multicolumn{2}{|l|}{$34 / 16$} & $17 / 13$ \\
\hline Hemoglobin (g/dL) & \multicolumn{2}{|l|}{$12.1( \pm 2.22)$} & $12.9( \pm 1.85)$ \\
\hline Leucocytes (/mm3) & \multicolumn{2}{|l|}{$9721( \pm 10972.3)$} & $7820( \pm 4469.3)$ \\
\hline Platelets /mm3 & \multicolumn{2}{|l|}{$20.772( \pm 16927.1)$} & $251.900( \pm 120674.3)$ \\
\hline $\mathrm{MPV} / \mathrm{fL}$ & \multicolumn{2}{|l|}{$11.35( \pm 2.50)$} & $8.70( \pm 1.03)$ \\
\hline HMGB1 levels (pg/mL) & \multicolumn{2}{|l|}{$15173.40( \pm 5312.51)$} & $5606.06( \pm 2298.67)$ \\
\hline \multicolumn{4}{|c|}{ Correlations } \\
\hline Platelet groups & HMGB1 levels (mean) pg/mL & $\begin{array}{c}\mathrm{p} \text { value } \& \\
\text { corelation coefficient }\end{array}$ & MPV levels (mean) fL \\
\hline$\geq 100.000 / \mathrm{mm} 3$ & $3786.1( \pm 2177.71)$ & 0.000 & 8.64 (SD 1.01) \\
\hline $31-99.000 / \mathrm{mm} 3$ & $13691.92( \pm 2797.83)$ & $\&$ & 11.43 (SD 3.8) \\
\hline$\leq 30.000 / \mathrm{mm} 3$ & $15501.57( \pm 5933.05)$ & 0.768 & 11.30 (SD 1.85) \\
\hline
\end{tabular}

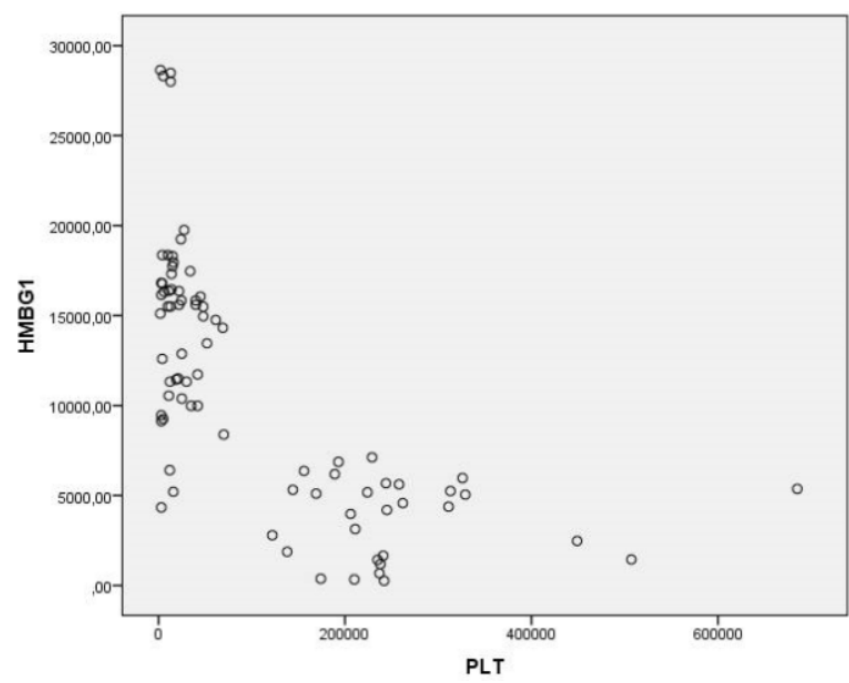

Figure 1. HMGB1 and Platelet Count

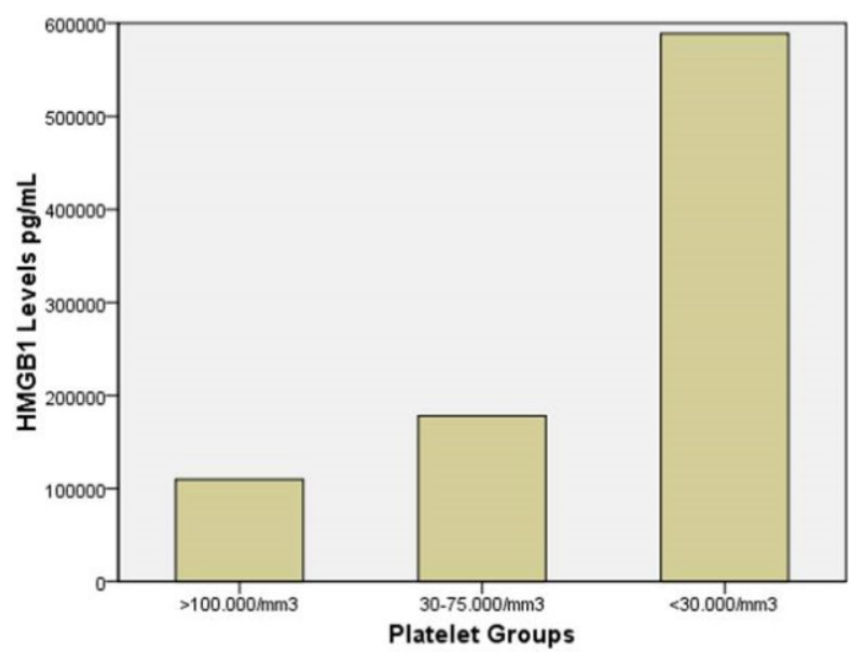

Figure 2. HMGB1 and Platelet Count Groups

MPV, which is a surrogate for increased platelet turnover within the pathogenesis of platelet destruction in ITP, was significantly related with increased HMGB1 levels ( $\mathrm{p}=0.001$, cc -0.532) (Figure 1 and 2).

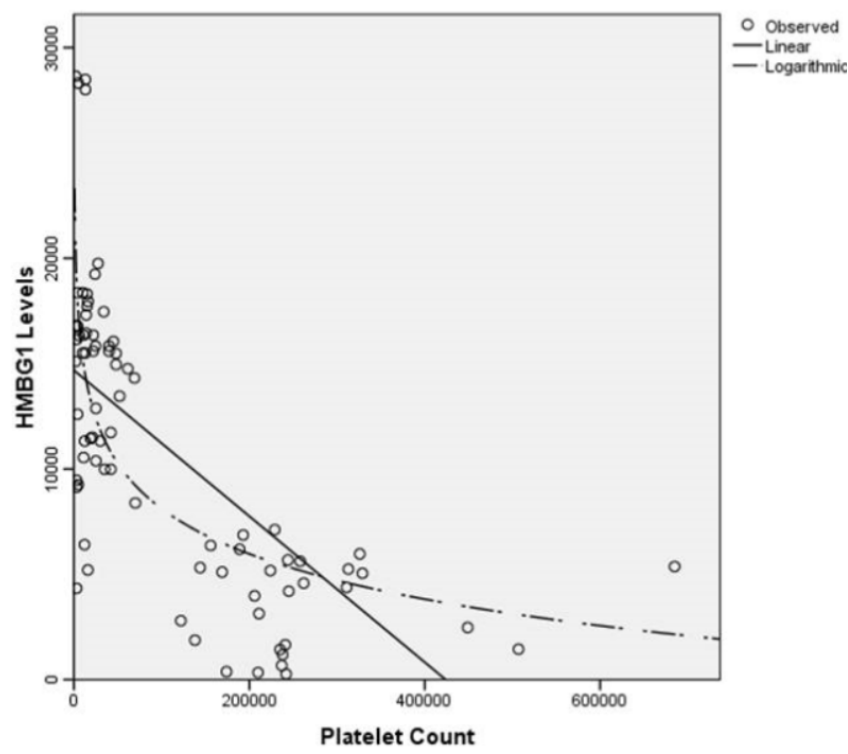

Figure 3. HMGB1 and Platelet Count Relations

As the patients and controls were grouped according to their platelet counts $(\geq 100.000 / \mathrm{mm} 3,31-99.000 / \mathrm{mm} 3$ and $\leq 30.000 / \mathrm{mm} 3$ ), HMGB1 levels were statistically different within the groups by ANOVA analysis and Post Hoc tests, higher in the group with platelets $<30.000 / \mathrm{mm} 3$. This significance was supported with logistical regression ( $p$ values, 0.002, 0.001 and 0.01, cc -0.7648) (Figure 3).

\section{Bleeding and HMGB1}

When presentation was taken into account, 16 patients presented with bleeding at the time of diagnosis (no major or life threatening bleeding, trivial bleeding including gingival bleeding and petechiae) in which 12 patients showed platelet counts less than 30.000 and 4 had $30.000-99.000 / \mathrm{mm} 3$ $(\mathrm{p}>0.05)$. MPV was not related with bleeding $(\mathrm{p}>0.05)$. Mean platelet counts in patients who have presented with bleeding was $21250 / \mathrm{mm} 3$ while in patients who did not have bleeding, 20542/mm3 (p>0.05).

In patients who have presented with bleeding, mean HMGB1 level was $18255,62 \mathrm{pg} / \mathrm{mL}$, while in patients without 


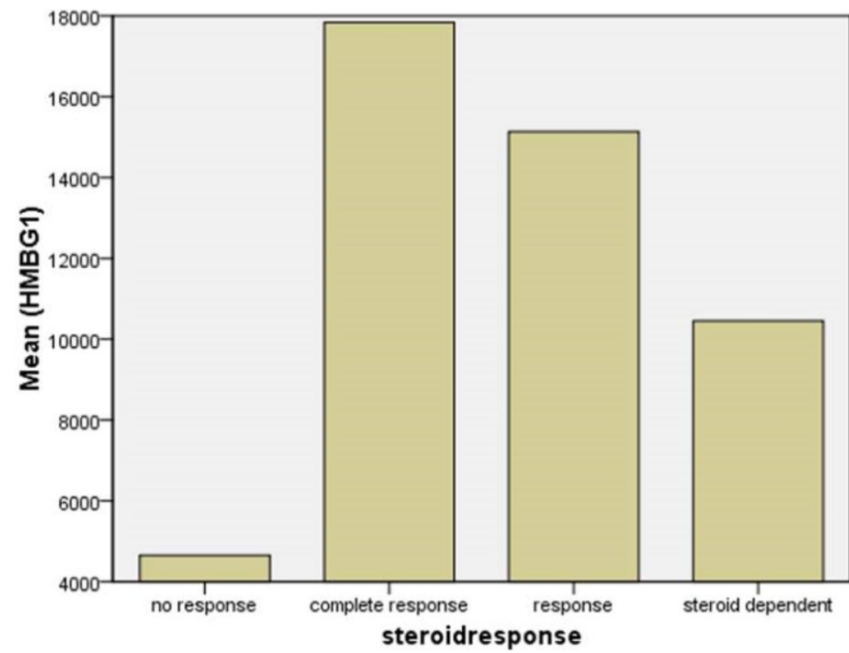

Figure 4. HMGB1 and Corticosteroid Response

bleeding, mean HMGB1 level was 13722,94 pg/mL ( $\mathrm{p}=0.002$, 95\% CI 9396.56-12524.3).

\section{Response to Treatment and HMGB1}

As the first line of treatment, response to treatment with $1 \mathrm{mg} / \mathrm{kg} /$ day methylprednisolone, 26 patients showed CR (32.5\%), 11 patients showed R (13.8\%), while 8 patient showed CD (10\%) and 5 patients showed no response (6.3\%). Regarding response evaluation, platelet count and MPV at presentation was not related with response ( $\mathrm{p}$ values $=0.143$, 0.377 respectively), while HMGB1 levels were related with response as patients with the highest HMGB1 levels were the best responders ( $\mathrm{p}=0.007$; and 95\%CI: 15769.19-19914.73) (Figure 4).

\section{DISCUSSION}

The leading hypothesis regarding the pathogenesis of ITP is autoantibody-mediated destruction of circulating platelets though reticuloendothelial system (the spleen) and Fc independent destruction of desialylated platelets [12] Besides this general explanation which is supported with the response to treatments against antibody-mediated immune system like intravenous immunoglobulin (IVIG) and splenectomy, the pathogenesis of ITP is unfortunately not that simple to be understood. The contribution and crosstalk of cellular immune system and the impairment or inhibition of megakaryopoiesis suggest much more complex pathways may be certain with a degree of individuality in each patient. The non-responders to corticosteroids, IVIG and splenectomy and trombopoietin agonists shall be predicted in advance for ideal but still hypothetical tailored treatment.

To better understand this complex inflammatory pathogenesis, many cytokines, chemokines have been and will be assessed. Generally in inflammatory responses, as the cytokines and chemokines are released to recruit both $\mathrm{T}$ cells as well as the activation of B cells, HMGB1 which is a DAMP protein, has been demonstrated to bind to multiple receptors in the including RAGE, TLRs, CXCR4 to amplify inflammatory signaling $[2,13]$. HMGB1 can be actively released through pathways including calcium signaling, TNF-alpha, Notch or NF-kB, MAPK, STAT or p53 dependent mechanisms and also passive released through cell death [2]. In septic conditions, HMGB1 can bind to pathogen associated pattern molecules of lipopolysaccharides and facilitate the activation of TLR2 and TLR4 mediated inflammation [7]. As such an ambidextrous molecule, HMGB1 is also connected with innate immunity with complement system through $\mathrm{C} 1 \mathrm{q}$ and activates classical pathway in an antibody dependent manner [14].

One step closer, HMGB1 is demonstrated to be located within the cytoplasm of platelets and recruited to the platelet membrane after activation [15]. Upon activation, HMGB1 could be released from platelets which is suggested to be related with conditions of high extracellular calcium [15]. Once it is released, HMGB1 binds to its receptors on platelets and promotes activation, granule secretion, adhesion and aggregation. By this interaction, HMGB1 is linked with various thrombotic conditions including coronary artery disease, ischemic stroke, venous thromboembolism and disseminated intravascular coagulopathy [16-19].

Our initial observation was the significant relation of higher HMGB1 levels with lower platelet counts. In DIC models, HMGB1 treatment was reported to result with an increase in platelet counts [17]. In our perspective, the initiator of disseminated coagulopathy should be the determinant of the outcome. A bacterial lipopolysaccharide may activate the TLR2 and TLR4 pathway and lead to increased production and release of platelets but sterile inflammation may activate not only TLR 2 and TLR 4 but also additional pathways including RAGE and TLR9 with varying degrees and lead to activation and eventually destruction of platelets and possibly, megakaryocytes [20]. Durations, strength and additional agonists of platelet activation and/or destruction may be responsible for the same molecule leading to different outcomes. In such inflammatory conditions, HMGB1 is demonstrated to play a significant role as a member of signal transduction [21-23].

The response to treatment may also be a good predictor for the pathogenetical value of any biomarker. From response to treatment back to pathogenesis, findings of HMGB1 in autoimmune processes have led to the inhibition of HMGB1 as a therapeutic target and responses to these treatments should be retrospectively assessed. Certain drugs are reported to inhibit HMGB1, including TNF-alpha inhibitors, corticosteroids, chloroquine, statins, and anticancer drugs cisplatine, daunomycine, methothrexate, which show their action towards humoral, cellular immune response or both. Antiagregant clopidogrel, anticoagulants heparin, thrombomodulin, danaparoid, antithrombin and activated protein $\mathrm{C}$ are also demonstrated to inhibit HMGB1 expression, release or activity [2-14,24]. Though the number of patients in our cohort is limited, we observed a very good 
response to corticosteroids in patients who have high HMGB1 levels. Though the previous study have demonstrated the expression of HMGB1 in the splenic tissues of chronic ITP patients which suggested its contribution to antibody-mediated immune activity, in our study we observed a relation with corticosteroid response, which may be regarded as a treatment majorly towards cellular immune response.

\section{LIMITATIONS}

The levels of extracellular HMGB1 may be evaluated not only with ELISA but also with Western Blot techniques. Response to each treatment steps, corticosteroids, intravenous immunoglobulin, splenectomy and more importantly, trombopoietin agonists should be investigated. HMGB1 levels may be used as a biomarker to predict the response to each step of treatment.

H.pylori status was not evaluated in our patients, as the treatment guidelines did not suggest the assessment of H.pylori in ITP patients [25]. In prospective larger studies, H.pylori, its virulance factors and relations with HMGB1 should be investigated.

Declaration of interest: The authors report no conflicts of interest.

Financial Disclosure: No financial support was received.

\section{REFERENCES}

1. Ugrinova I, Pasheva E. HMGB1 Protein: A Therapeutic Target Inside and Outside the Cell. Adv Protein Chem Struct Biol. 2017;107:37-76. doi: 10.1016/bs.apcsb.2016.10.001. Epub 2016 Dec 2.

2. Kang R, Chen R, Zhang Q, Hou W, Wu S, Cao L, Huang J, Yu Y, Fan XG, Yan Z, Sun X, Wang H, Wang Q, Tsung A, Billiar TR, Zeh HJ 3rd, Lotze MT, Tang D. HMGB1 in health and disease. Mol Aspects Med. 2014 Dec;40:1116. doi: 10.1016/j.mam.2014.05.001. Epub 2014 Jul 8.

3. Yanai H, Ban T, Wang Z, Choi MK, Kawamura T, Negishi H, Nakasato M, Lu Y,Hangai S, Koshiba R, Savitsky D, Ronfani L, Akira S, Bianchi ME, Honda K, Tamura T, Kodama T, Taniguchi T. HMGB proteins function as universal sentinels for nucleic-acidmediated innate immune responses. Nature. 2009 Nov 5;462(7269):99-103. doi: 10.1038/nature08512.

4. Qiu Y, Yang J, Wang W, Zhao W, Peng F, Xiang Y, Chen G, Chen T, Chai C, Zheng S, Watkins DJ, Feng J. HMGB1-promoted and TLR2/4-dependent NK cell maturation and activation take part in rotavirus-induced murine biliary atresia. PLoS Pathog.2014 Mar 20;10(3):e1004011. doi: 10.1371/journal.ppat.1004011.

5. Bauer EM, Shapiro R, Billiar TR, Bauer PM. High mobility group Box 1 inhibits human pulmonary artery endothelial cell migration via a Toll-like receptor 4- and interferon response factor 3-dependent mechanism(s). J Biol Chem. 2013 Jan 11;288(2):1365-73. doi: 10.1074/jbc.M112.434142.
6. Scaffidi P, Misteli T, Bianchi ME. Release of chromatin protein HMGB1 by necrotic cells triggers inflammation. Nature. 2002 Jul 11;418(6894):191-5. doi: 10.1038/nature00858

7. Yang H, Hreggvidsdottir HS, Palmblad K, Wang H, Ochani M, Li J, Lu B, Chavan S, Rosas-Ballina M, AlAbed Y, Akira S, Bierhaus A, Erlandsson-Harris H, Andersson U, Tracey KJ. A critical cysteine is required for HMGB1 binding to Toll-like receptor 4 and activation of macrophage cytokine release. Proc Natl Acad Sci U S A. 2010 Jun 29;107(26):11942-7. doi: 10.1073/pnas.1003893107.

8. Kang R, Zhang Q, Zeh HJ 3rd, Lotze MT, Tang D. HMGB1 in cancer: good, bad, or both? Clin Cancer Res. 2013 Aug 1;19(15):4046-57. doi: 10.1158/10780432.CCR-13-0495. Epub 2013 May 30.

9. Yang PF, Zhang GY, Liu HY, Xie SF, Wang XJ, Liu XY, Wang J, Chen XY, Yang S,Ma LP. [Expression of HMGB1 in Spleen of Adult Patients with Chronic and Refractory Immune Thrombocytopenia and Its Significance]. Zhongguo Shi Yan Xue Ye Xue Za Zhi. 2018 Apr;26(2):516-521. doi: 10.7534/j.issn.10092137.2018.02.035.

10. Rodeghiero F, Stasi R, Gernsheimer T, Michel M, Provan D, Arnold DM, Bussel JB, Cines DB, Chong BH, Cooper N, Godeau B, Lechner K, Mazzucconi MG, McMillan R,Sanz MA, Imbach P, Blanchette V, Kühne T, Ruggeri M, George JN. Standardization of terminology, definitions and outcome criteria in immune thrombocytopenic purpura of adults and children: report from an international working group. Blood. 2009 Mar 12;113(11):2386-93. doi: 10.1182/blood-2008-07-162503.

11. Neunert C, Lim W, Crowther M, Cohen A, Solberg L Jr, Crowther MA; American Society of Hematology. The American Society of Hematology 2011 evidence-based practice guideline for immune thrombocytopenia. Blood. 2011 Apr 21;117(16):4190-207. doi: 10.1182/blood-2010-08-302984.

12. Toltl LJ, Arnold DM. Pathophysiology and management of chronic immune thrombocytopenia: focusing on what matters. Br J Haematol. 2011 Jan;152(1):52-60. doi: 10.1111/j.1365-2141.2010.08412.x. Epub 2010 Nov 18.

13. Venereau E, Schiraldi M, Uguccioni M, Bianchi ME. HMGB1 and leukocyte migration during trauma and sterile inflammation. Mol Immunol. 2013 Aug;55(1):7682. doi: 10.1016/j.molimm.2012.10.037.

14. Kim SY, Son M, Lee SE, Park IH, Kwak MS, Han M, Lee HS, Kim ES, Kim JY, Lee JE, Choi JE, Diamond B, Shin JS. High-Mobility Group Box 1-Induced Complement Activation Causes Sterile Inflammation. Front Immunol. 2018 Apr 11;9:705. doi: 10.3389/fimmu.2018.00705. 
15. Yang $\mathrm{X}$, Wang $\mathrm{H}$, Zhang $\mathrm{M}$, Liu J, Lv B, Chen F. HMGB1: a novel protein that induced platelets active and aggregation via Toll-like receptor-4, NF- $\kappa \mathrm{B}$ and cGMP dependent mechanisms. Diagn Pathol. 2015 Aug 6;10:134. doi: 10.1186/s13000-015-0348-3.

16. Wu H, Li R, Pei LG, Wei ZH, Kang LN, Wang L, Xie J, Xu B. Emerging Role of High Mobility Group Box-1 in Thrombosis-Related Diseases. Cell Physiol Biochem. 2018;47(4):1319-1337. doi: 10.1159/000490818.

17. Ito T, Kawahara K, Nakamura T, Yamada S, Nakamura T, Abeyama K, Hashiguchi T, Maruyama I. Highmobility group box 1 protein promotes development of microvascular thrombosis in rats. J Thromb Haemost. 2007 Jan;5(1):109-16.

18. Takahashi T, Shishido T, Kinoshita D, Watanabe K, Toshima T, Sugai T, Narumi T, Otaki Y, Tamura H, Nishiyama S, Arimoto T, Takahashi H, Miyamoto T, Watanabe T, Woo CH, Abe JI, Takeishi Y, Kubota I, Watanabe M. Cardiac Nuclear High-Mobility Group Box 1 Ameliorates Pathological Cardiac Hypertrophy by Inhibiting DNA Damage Response. JACC Basic Transl Sci. 2019 Apr 29;4(2):234-247.

19. Ye Y, Zeng Z, Jin T, Zhang H, Xiong X, Gu L. The Role of High Mobility Group Box 1 in Ischemic Stroke. Front Cell Neurosci. 2019 Apr 2;13:127

20. Yu S, Zhang H, Hei Y, Yi X, Baskys A, Liu W, Long Q. High mobility group box-1 (HMGB1) antagonist BoxA suppresses status epilepticus-induced neuroinflammatory responses associated with Toll-like receptor 2/4 down-regulation in rats. Brain Res. 2019 Apr 12. pii: S0006-8993(19)30200-8.
21. Frank MG, Annis JL, Watkins LR, Maier SF. Glucocorticoids mediate stress induction of the alarmin HMGB1 and reduction of the microglia checkpoint receptorCD200R1 in limbic brain structures. Brain Behav Immun. 2019 May 9. pii:S0889-1591(19)30279.

22. Meng R, Gu L, Lu Y, Zhao K, Wu J, Wang H, Han J, Tang Y, Lu B. High mobility group box 1 enables bacterial lipids to trigger receptor-interacting protein kinase 3 (RIPK3)-mediated necroptosis and apoptosis in mice. J Biol Chem. 2019 Apr 18. pii: jbc.RA118.007040.

23. Nakamura T, Kashima K, Takahashi N, Yamada S. Serum high mobility group box-1 and cytokine profiles in a leukemoid reaction. Pediatr Int. 2019 Apr;61(4):427-429

24. Chen C, Wang S, Chen J, Liu X, Zhang M, Wang X, Xu W, Zhang Y, Li H, Pan X,Si M. Escin suppresses HMGB1-induced overexpression of aquaporin-1 and increased permeability in endothelial cells. FEBS Open Bio. 2019 May;9(5):891-900.

25. Lin HJ, Hsu FY, Chen WW, Lee CH, Lin YJ, Chen YY, Chen CJ, Huang MZ, Kao MC, Chen YA, Lai HC, Lai $\mathrm{CH}$. Helicobacter pylori Activates HMGB1 Expression and Recruits RAGE into Lipid Rafts to Promote Inflammation in Gastric Epithelial Cells. Front Immunol. $2016 \quad$ Sep 9;7:341. doi: 10.3389/fimmu.2016.00341. 